\title{
Frequency-based time-series gene expression recomposition using PRIISM
}

Bruce A Rosa ${ }^{1,2 \dagger}$, Yuhua Jiao ${ }^{2 \dagger}$, Sookyung O ${ }^{2}$, Beronda L Montgomery ${ }^{2,3}$, Wensheng Qin ${ }^{1 *}$ and Jin Chen ${ }^{2,4^{*}}$

\begin{abstract}
Background: Circadian rhythm pathways influence the expression patterns of as much as $31 \%$ of the Arabidopsis genome through complicated interaction pathways, and have been found to be significantly disrupted by biotic and abiotic stress treatments, complicating treatment-response gene discovery methods due to clock pattern mismatches in the fold change-based statistics. The PRIISM (Pattern Recomposition for the Isolation of Independent Signals in Microarray data) algorithm outlined in this paper is designed to separate pattern changes induced by different forces, including treatment-response pathways and circadian clock rhythm disruptions.

Results: Using the Fourier transform, high-resolution time-series microarray data is projected to the frequency domain. By identifying the clock frequency range from the core circadian clock genes, we separate the frequency spectrum to different sections containing treatment-frequency (representing up- or down-regulation by an adaptive treatment response), clock-frequency (representing the circadian clock-disruption response) and noise-frequency components. Then, we project the components' spectra back to the expression domain to reconstruct isolated, independent gene expression patterns representing the effects of the different influences.

By applying PRIISM on a high-resolution time-series Arabidopsis microarray dataset under a cold treatment, we systematically evaluated our method using maximum fold change and principal component analyses. The results of this study showed that the ranked treatment-frequency fold change results produce fewer false positives than the original methodology, and the 26-hour timepoint in our dataset was the best statistic for distinguishing the most known cold-response genes. In addition, six novel cold-response genes were discovered. PRIISM also provides gene expression data which represents only circadian clock influences, and may be useful for circadian clock studies.

Conclusion: PRIISM is a novel approach for overcoming the problem of circadian disruptions from stress treatments on plants. PRIISM can be integrated with any existing analysis approach on gene expression data to separate circadian-influenced changes in gene expression, and it can be extended to apply to any organism with regular oscillations in gene expression patterns across a large portion of the genome.
\end{abstract}

\section{Background}

Differential gene expression studies typically use the fold change statistic (the ratio of mRNA quantities between two samples) as input, and have been used to discover genes involved in adaptive stress responses which have not been previously characterized (i.e., "novel genes") [1]. Specifically, to correct for changes in gene expression induced by non-treatment related influences, foldchange values for time-series data are usually calculated

\footnotetext{
* Correspondence: wqin@lakeheadu.ca; jinchen@msu.edu

${ }^{\dagger}$ Equal contributors

'Biorefining Research Initiative and Department of Biology, Lakehead University, 955 Oliver Road, Thunder Bay, ON P7B 5E1, Canada Full list of author information is available at the end of the article
}

using treatment and control data at every timepoint [1]. One of the major factors causing gene oscillations under control conditions is the molecular circadian clock, which influences physiology and metabolism in preparation for predictable changes in light and temperature [2]. However, a wide range of biotic and abiotic stress treatments have been shown to disrupt rhythmic clock patterns through amplitude changes or phase shifts [38], resulting in significant fold changes for genes which are clock-influenced but are not involved in direct stress response. Figure 1 demonstrates that genes can be differentially regulated due to direct stress responses (I), indirectly differentially regulated through disruption of clock pathways induced by the stress (II) or a combination of

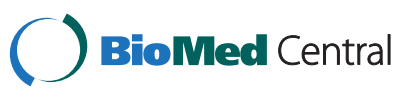




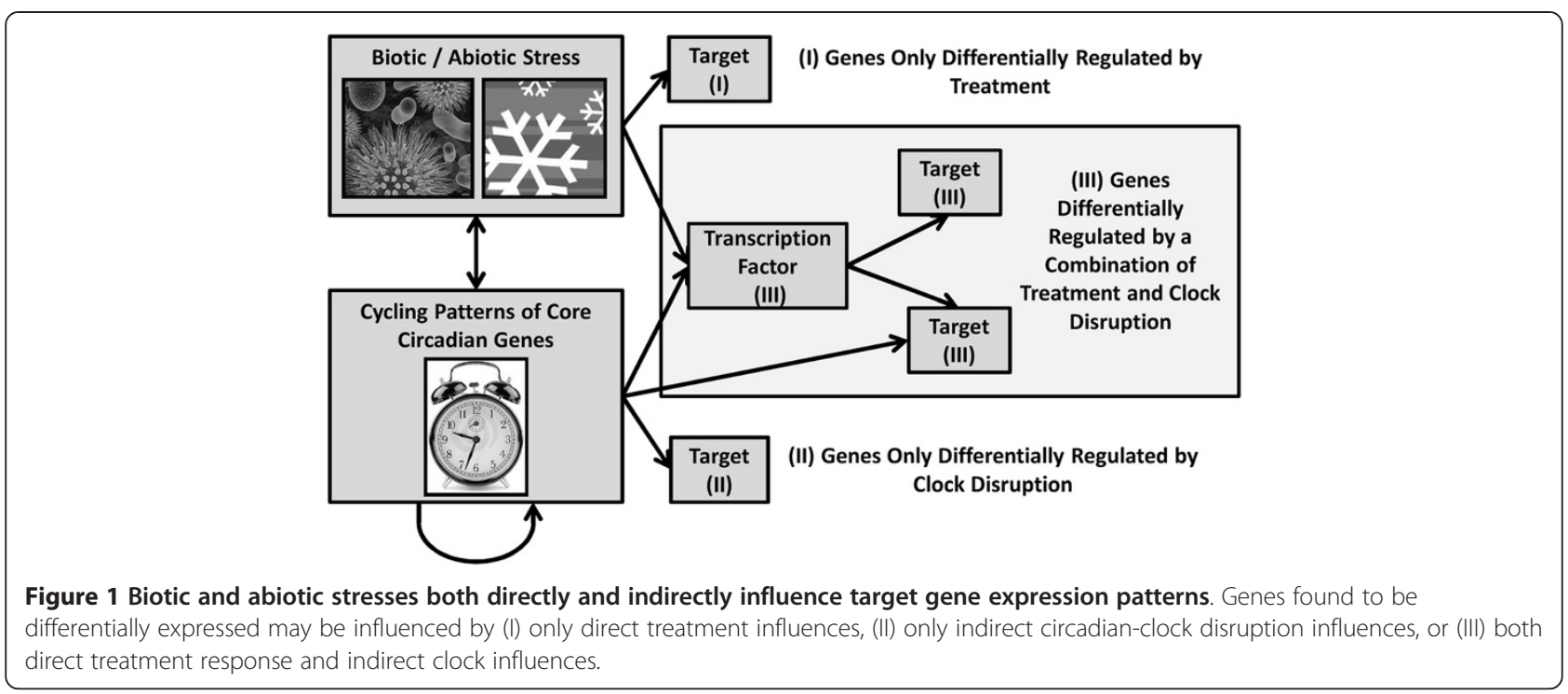

both (III). Additional complications in regulation patterns arise from the complexity of transcription factor pathways, in which targets may be regulated by clock components directly or through interactions with their transcription factors (Figure 1). For this reason, novel treatment-response gene discovery methods are complicated by the disruption of synchronization of the circadian rhythm pathways, but this complexity is not reflected in existing methods including fold change studies, clustering analysis approaches, and more complex time-serial-based algorithms [1,2,5,6,9-17].

In this paper, we present the PRIISM (Pattern Recomposition for the Isolation of Independent Signals in Microarray data) algorithm to perform novel stressresponse gene discovery analyses which correct for differential gene expression patterns induced by the circadian clock. As described previously [6], although core circadian clock gene patterns undergo significant changes in phase and amplitude as a result of stress, they maintain oscillating frequencies which remain similar to each other, and still remain close to the circadian pattern of one cycle per day. It has also been shown that stress results in significantly increased average expression levels for stress-response genes [6], which are reflected in the low-frequency signals (where one oscillation cycle occurs over the course of several days) for these genes. We assume that although circadian clock influences and adaptive stress-response influences can interact with each other (Figure 1), they still cycle at very different rates from each other (and therefore maintain separate dominant frequency ranges) under stress conditions. Based on these observations, we have developed PRIISM to project gene expression data to the frequency domain using the Fourier Transform, isolate independent signals, and then project them back to the expression domain to reconstruct independent gene expression patterns representing the effects of different genetic influences. PRIISM is capable of separating one gene expression pattern into three distinct gene expression patterns: (1) The treatment-frequency gene expression pattern, which has much of the complicating circadian influences removed, and consequently can be used to more accurately identify differentially regulated genes which are involved in direct treatment response, (2) the clock-frequency gene expression pattern, representing rhythmic patterns with a period of approximately one cycle per day, and (3) the noise-frequency gene expression pattern (Figure 2). By applying PRIISM on a cold-treatment dataset, we demonstrate that it can identify known treatment-response genes with a much lower false-positive rate than the existing methods, and can also identify important regulatory timepoints which are not obvious in the unprocessed data. In addition to improving performance when conducting novel treatment-response gene discovery, PRIISM also provides gene expression data which represent only circadian clock influences, and may be useful for circadian clock analysis studies.

Biological approaches such as the use of constant light and clock component genetic knockout mutants are applied in order to attempt to remove the influences of the circadian clock on target gene expression. However, constant light is an unnatural condition which reduces the applicability of the results, because natural biotic and abiotic genetic stress-response patterns depend on the time-of-day (the point in the light/dark cycle) at which the treatment is applied $[6,18,19]$. Likewise, the use of genetic knockout mutants of circadian clock genes can reduce disruptions due to circadian input; However, since stress response genes may be regulated by clock 


\section{b PRIISM-Processed Gene Expression and Fold Change Data}

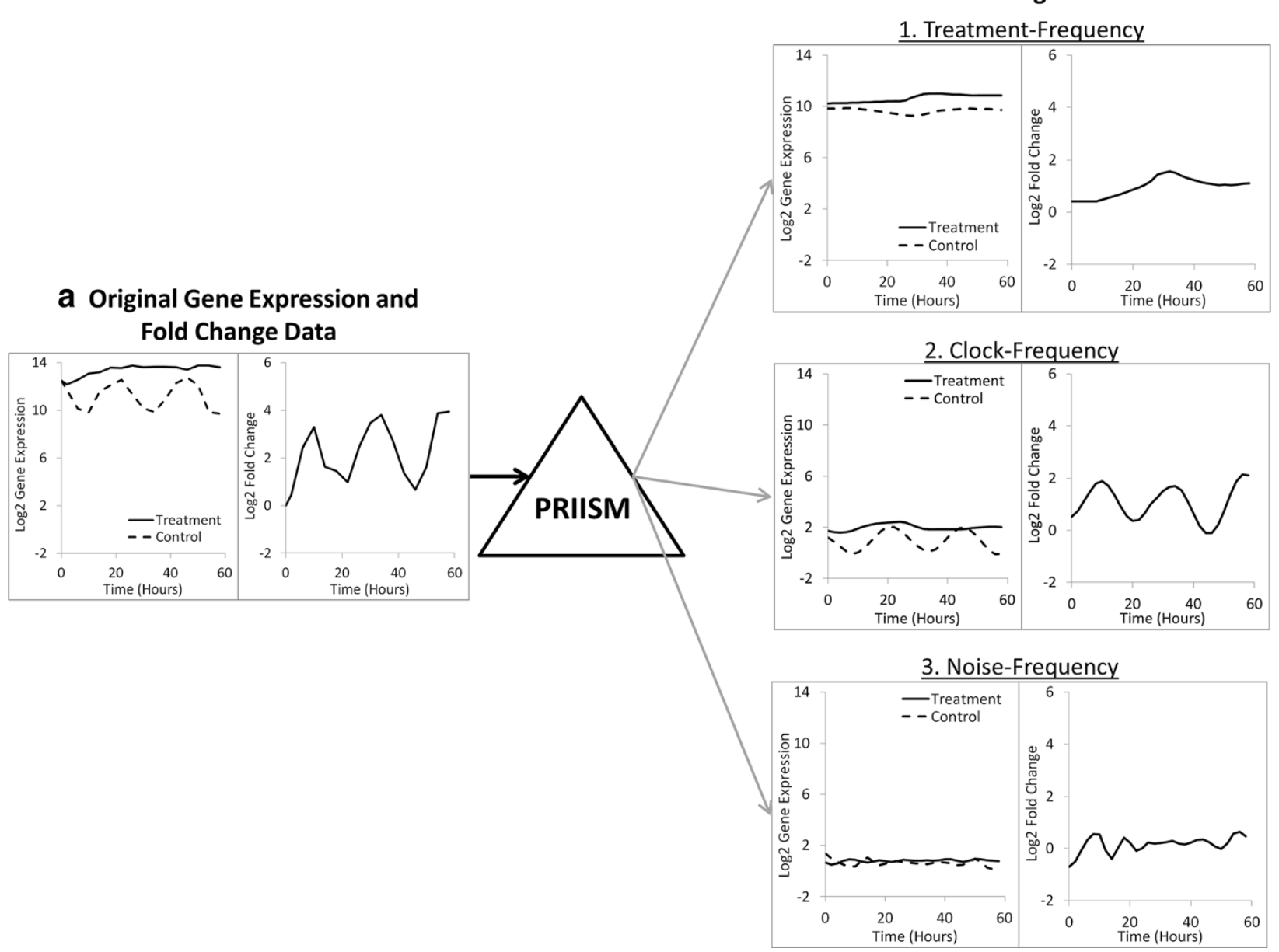

Figure 2 PRIISM separates gene expression data into three independent gene expression datasets. PRIISM separates (A) the original gene expression patterns under control and treatment conditions (used to calculate the fold change pattern) into (B) treatment-frequency, clockfrequency and noise-frequency gene expression patterns. The cold-induced gene COR15A (AT2G42540) is shown as an example.

components, the results of such a study are also difficult to interpret $[7,19,20]$.

Most existing computational approaches for studying differential gene expression in microarray datasets involve clustering algorithms designed to group genes with similar expression profiles, with the goal of identifying potential annotations for unknown genes [10-17]. However, the gene distance measures used by all of these clustering methods are unable to distinguish adaptiveresponse gene expression patterns from circadian clock disruption gene expression patterns, and so may cluster genes with similar clock influences but very different treatment-response influences. Bar-Joseph et al's (2003) continuous representation model for finding differentially expressed genes in time series micro array datasets (which has been used to find more cell-cycle response genes in yeast than conventional clustering methods) is also unable to filter clock influences from treatment response influences on gene expression patterns [21].

Several studies have shown that between $6 \%$ and $31 \%$ of the Arabidopsis genome is influenced by circadian clock genetic components [5,22,23]; while another study suggests that there are significant baseline circadian oscillations for nearly $100 \%$ of the genome [24]. A number of approaches have been developed for analyzing the circadian rhythms of genes in time-series datasets $[5,25-$ 28]. Fourier analysis (which can be used to identify dominant frequencies in time-series data) has been applied to successfully identify periodic genes by treating timeseries microarray datasets as time-domain signals [2832]. However, these Fourier analysis methods have not been widely used in differential gene expression study methods, because 1) in existing Fourier analysis applications [28-32], a fixed frequency range was used as a 
priori knowledge to discover genes with similar oscillations, but novel genes may have totally different frequency patterns under different treatment conditions and; 2) to accurately capture oscillating rhythms, high resolution time course gene expression data is essential according to Nyquist sampling theorem [25,33], but such data have not been available until recently.

As the price of running microarrays and RNA-seq chips continues to fall, high-resolution time-series gene expression datasets that contain enough information to identify and characterize circadian-frequency rhythms for every gene are becoming available [34-36]. Recently, Espinoza et al. (2010) produced one such microarray dataset, which measured 16 timepoints covering a 58hour time period with a cold treatment in Arabidopsis [7]. Cold-stress genetic responses in Arabidopsis are particularly well-characterized, and have been shown to significantly dampen and phase-shift the oscillations of the core clock genes $C C A 1$ and $L H Y$, which have regulatory influences over some cold-responsive transcription factors, including CBF1, CBF2 and CBF3 [20]. Disruption of the expression patterns of other circadian output marker genes due to cold treatment has also been reported, including constant over expression of $C A B 2$ and CCR2, and constant underexpression of $C A T 3$ [6,9]. For these reasons, this is an ideal dataset to test whether the PRIISM algorithm is able to separate the strong circadianclock influences on cold-response genes from treatmentresponse influences.

\section{Methods}

A wide range of biotic and abiotic stress treatments have been shown to significantly disrupt the cyclic patterns of core circadian clock genes and their downstream target genes [3-8]. When a stress treatment is constantly applied, adaptive stress-response genes are expected to be differentially regulated, while influences from the circadian clock will cause oscillations in target gene expression patterns. In PRIISM, by projecting the gene expression data to the frequency domain using the Fourier transform [37], the resulting amplitude spectra peak at different frequencies, caused by these different influences. The Fourier transform is a mainstream signal processing technique that simplifies period gram analysis by identifying the dominant frequencies in the amplitude spectrum. By distinguishing the clock frequency range from the core circadian clock genes in the frequency domain, we can separate the spectrum to different sections containing treatment-related, clock-related and noiserelated influences. Then, we project the amplitude spectra back to the expression domain to reconstruct isolated, independent gene expression patterns representing the effects of different frequency components. This method can be applied to any dataset which has sufficiently high resolution and length to measure frequencies of at least one cycle per day, and which uses a treatment which is applied at a frequency significantly different than the clock frequency.

PRIISM has four steps (Figure 3). In the first step, gene expression data are pre-processed to fit the requirements of the Fourier transform, after which the Fourier transform is performed to produce an amplitude spectrum for every gene (Figure $3 \mathrm{~A}, 3 \mathrm{~B}$ ). In the second step, a clock vector that defines the frequency range and the amplitudes of the core circadian clock genes is identified based on the spectra of core circadian clock genes (Figure 3C). In the third step, the clock vector is used to decompose every gene's spectrum into three components (treatment, clock and noise; Figure 3D). In the final step, the inverse Fourier transform is applied to project each spectrum component back to the expression domain, resulting in three independent expression patterns (Figure 3E, 3F).

\section{Pre-processing and Fourier analysis}

Time series gene expression data are often unevenly sampled, and the disruption of clock patterns caused by the treatment varies over time. To be able to apply the Fourier transform (which requires steady and evenly sampled input), pre-processing is required. First, the whole time course is divided into overlapped frames. The size of these frames can be changed depending on the experiment; If they are too long, then it may be difficult to capture changes over time, and if they are too short, then it is more difficult to capture the treatmentfrequency patterns (particularly for low-resolution data). For this experiment, the first time frame is 26 hours long due to the two-hour light period at the start of the time period, and all the other time frames are 24 hours long, starting and ending at each light/dark transition (Additional file 1: Figure S1A). Second, within each time frame, the gene expression data is interpolated (making the time points evenly sampled), and the mean of the gene expression data for each gene is shifted to zero (refer to explanation of Eq. 2). The Fourier transform is then applied on each overlapping time frame individually, and the final expression values for each timepoint are calculated using a weighted average for each time frame, where higher weights are used for expression values near the center of each time frame (Additional file 1: Figure S1B).

Fourier analysis is a signal processing technique [37] for the study of two processes: The Fourier transform (the process of decomposing a signal into a sum of components with different frequencies) and the inverse Fourier transform (the operation of reconstructing the signal from these components). Specifically, the discrete Fourier transform (DFT) and its inverse have been used 


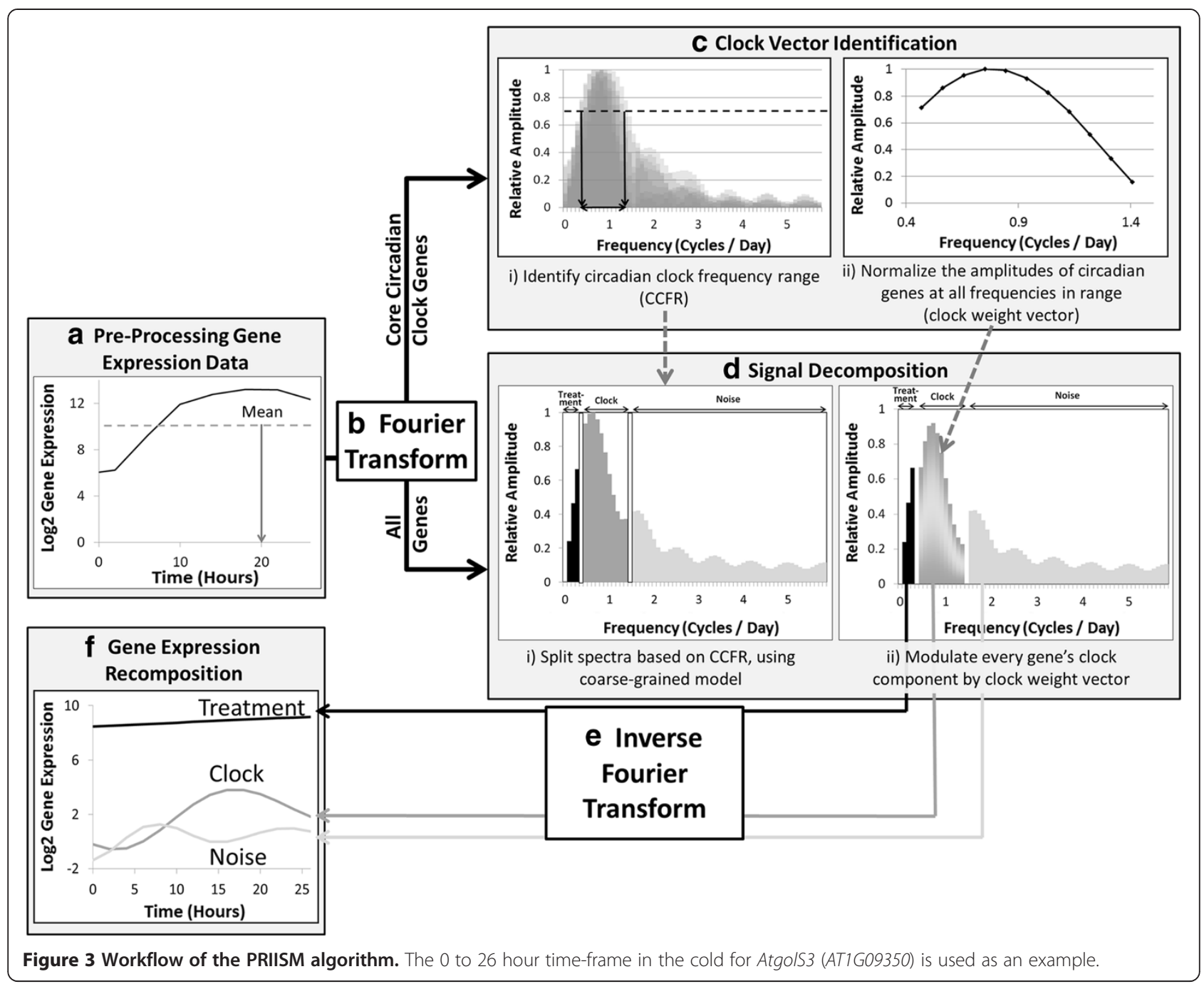

to transform gene expression signals and to reconstruct the discrete signal, respectively [38]. The Fourier coefficient of DFT $\left(G_{n}\right)$ measures the contribution of the corresponding frequency component to the original signal and is given in Eq. 1 [37]:

$$
G_{n}=\sum_{k=0}^{K-1} g(k T) e^{-i 2 \pi \frac{n}{N T} k} \quad n=0, \ldots, N-1
$$

where, $g(k T)$ is the sampled signal of $K$ samples with the sampling interval $T ; i$ is the imaginary unit. The frequency of the corresponding component $n$ is denoted as $f_{n}$ (i.e., $\frac{n}{N T}$ ), where $N$ is the number of frequency components. The DFT maps a time course signal into the frequency domain by producing a spectrum. An amplitude spectrum (plotted as the amplitude versus frequency) is a common frequency domain representation of the original signal. Fast Fourier transform (FFT) is an efficient algorithm to compute the DFT and its inverse [37].
Because of its popularity, it has been built into most modern analysis tools including MATLAB and $\mathrm{R}$ $[39,40]$.

The Fourier coefficient of the zero-frequency component $\left(G_{0}\right)$, derived from Eq. (1) where $f_{n}=0$, is shown in Eq. 2 as given in [37]:

$$
G_{0}=\sum_{k=0}^{K-1} g(k T) e^{-i 2 \pi k * 0}=\sum_{k=0}^{K-1} g(k T)
$$

Note that there is a dominant peak at zero frequency in the spectrum of the expression value, which may bias the identification of the true dominant peak to frequency zero. To avoid such bias, we shift the mean of the time course gene expression values for each gene to zero (and consequently $G_{0}=0$ ), leading to the removal of the peak at zero frequency. For example, the mean expression value for the gene shown in Figure 3A is reduced from 10.6 to 0, and will be added back proportionally to the reconstructed gene expression values during signal recomposition. 


\section{Identification of the circadian clock frequency range}

The Arabidopsis circadian clock is composed of multiple feedback loops. Three genes, Circadian Clock Associated 1 (CCA1), Late Elongated Hypocotyl (LHY) and Timing of CAB Expression 1 (TOC1) compose the first and most important feedback loop controlling the circadian clock, while Pseudo Response Regulators 7 and 9 (PRR7 and $P R R 9)$ form a secondary feedback loop with CCA1 and $L H Y$, and a third feedback loop involving TOC1 is regulated by unknown components [41,42]. It has been found that through these feedback loops, eight core circadian clock genes (CCA1, LHY, PRR7, PRR9, ELF4, GI, $L U X$ and TOC1) and their downstream gene targets regulate a wide range of downstream pathways, including germination, leaf development, organelle morphology, photosynthesis, and cell wall development [2,18,43-46].

The Fourier transform is performed on these eight core circadian genes (Figure 3Ci). The frequency components with relative amplitudes greater than 0.7 (corresponding to half of the maximum value in the spectra) are chosen as dominant frequencies [47]. We define the union of these eight sets of dominant frequencies as Circadian Clock Frequency Range (CCFR), noted as $\left[f_{c_{-} \min }, f_{c_{-} \max }\right]$, where $f_{c_{\_} \min }$ is the lowest frequency, and $f_{c_{-} \text {max }}$ is the highest frequency (Figure $3 \mathrm{Ci}$ ). Note that in this example, the dominant clock frequency is significantly lower than one cycle per day, due to the stressinduced disruption of clock patterns. The weight of each frequency component in the CCFR is derived as:

$$
w_{n}=\frac{\sum_{m=1}^{8}\left|G_{m n}\right|^{2}-\min (G)}{\max (G)-\min (G)} \quad n \in\left[c \_ \text {min }, c \_ \text {max }\right]
$$

where $\left|G_{m n}\right|$ is the magnitude of the Fourier coefficient of the $n_{t h}$ frequency component for the $m_{t h}$ core circadian gene, $\quad G=\left\{\sum_{m=1}^{8}\left|G_{m c_{-} m i n}\right|^{2}, \sum_{m=1}^{8}\left|G_{m\left(c_{-} \text {min }+1\right)}\right|^{2}, \ldots\right.$, $\left.\sum_{m=1}^{8}\left|G_{m c_{-} \max }\right|^{2}\right\}$ is the set of the summed power of eight core clock genes present at each frequency component within the Circadian Clock Frequency Range (CCFR), and $w_{n}$ is the weight for the frequency component at frequency $f_{n}$. The vector $\left\{w_{c \_ \text {min }}, w_{c_{\_} \text {min }+1}, \ldots, w_{c_{-} \text {max }}\right\}$ defines the gainfrequency response of a tapering bandpass filter within the CCFR.

\section{Signal decomposition and recomposition}

We apply Fourier analysis on each gene, producing the relative amplitude spectrum from which we identify three distinct sections: Treatment-frequency, clockfrequency and noise-frequency components (Figure 3Di). For the treatment-frequency decomposition, given a relatively narrow frequency band, we used a low pass filter with a steep cut-off frequency to gain the optimal balance between removing ringing artifact and approximating desired frequency response [48]. This issue is addressed in detail in the "Justification for choosing a steep cut-off frequency for the low-pass filter" section of the (Additional file 1: Figure S3, Figure S4 and Figure S5) [49].

The clock component is derived by bandpass filtering. Fourier coefficients of the clock components of each gene are modulated by the weight of the corresponding frequency components, as given by Eq. 4:

$$
\hat{G}_{c}=w_{c} G_{c} \quad c \in\left[c \_ \text {min, } c \_ \text {max }\right]
$$

The tapering filtering results in clock-frequency expression patterns that are noise reduced and with less artifacts caused by a discontinuity in the filter function. The reconstructed high frequency expression pattern is considered to be noise, and it is not studied in this paper. Therefore, we simply applied an ideal high pass filter. The reweighted spectra used for the signal reconstruction of the three frequency components sections are shown in Figure 3Dii.

The inverse discrete Fourier transform (IDFT) is calculated according to Eq. 5 [37]:

$$
g(k T)=\frac{1}{N} \sum_{n=0}^{N-1} G_{n} e^{i 2 \pi \frac{n}{N T} k} \quad k=0, \ldots, K-1
$$

The inverse Fourier transform is performed on the full spectrum, including the filtered spectra for each gene. Similar to using the clock vector as a tapering band-pass filter to remove noise, we added a coarse graining process to make sure there is no overlapping between any of the two frequency bands, which may increase the robustness of component selection. The mean of the original gene expression values (which was removed in the pre-processing step), is added back proportionally to each gene expression curve based on the amplitude distribution of each component in the spectra before shifting the mean (Figure 3F), according to Eq. 6:

$$
g_{L}^{\prime}(k T)=g_{L}(k T)+\frac{\sum_{k=0}^{K-1} g(k T) \sum\left|G_{L}^{0}\right|^{2}}{K \sum\left|G_{n}^{0}\right|^{2}} k=0, \ldots, K-1
$$

where $g_{L}^{\prime}(k T)$ is the treatment expression level at timepoint $k T$ for a given gene, $g_{L}(k T)$ is a result of inverse discrete Fourier transform (Eq. 5) on treatment frequency at timepoint $k T, G_{n}^{0}$ is the Fourier coefficient of original gene expression values and $G_{L}^{0}$ is the Fourier coefficient of original gene expression values in the treatment-frequency band $\left[0, f_{c_{-} \min ^{-}}-1\right]$. Similarly, we 
compute $g_{C}^{\prime}(k T)$ and $g_{N}^{\prime}(k T)$ i.e., the clock expression level and noise level.

Note that because the entire warm and cold gene expression datasets are mean-shifted based on their relative amplitudes in each component, the reconstructed time-zero fold change values may not necessarily be equal to zero (Figure 2B).

\section{Results and discussion}

This study analyzes an Arabidopsis Affymetrix ATH1 microarray dataset (containing 22,810 probes) generated by Espinoza et al. (2010), which consists of 16 timepoints collected over the course of 58 hours in both warm $\left(20{ }^{\circ} \mathrm{C}\right)$ and cold $\left(4{ }^{\circ} \mathrm{C}\right)$ conditions under a 16-hour light/8-hour dark cycle starting at ZT14 (14 hours after dawn) [7]. This dataset was chosen for the analysis because it has separate control and treatment arrays, it has sufficiently high resolution (sampled at 2 hours and every 4 hours after that), and cold is a well-studied treatment in Arabidopsis $[6,7,9,20,50,51]$.

Gene expression data was RMA normalized using the "affylmgui" program available as part of the Bioconductor software package and annotated using annotation data available from TAIR (version 10, available ftp://ftp.arabidopsis.org/Genes/TAIR10_genome_release/). The gene expression data were interpolated to every 2 hours using $\mathrm{B}$-spline regression, and were segmented into four overlapping gene expression time frames (from both the warm and cold treatments), which were combined using a weighted average (Additional file 1: Figure S1) [52,53]. PRIISM was applied on this "original" dataset, resulting in three independent and isolated gene expression datasets (treatment-frequency, clock-frequency and noisefrequency).

\section{Treatment-response gene discovery}

In order to show the advantage of PRIISM, we identified known cold-response genes using maximum fold changes and principal component analysis in the treatment-frequency dataset compared to the original dataset. Fold change values were calculated by subtracting the logged gene expression value in the warm from the logged gene expression value in the cold at every timepoint. Lists of Arabidopsis genes upregulated by cold treatment when grown on agar plates or grown in soil were collected from a previous study by Vogel et al [54]. The 302 cold-upregulated genes found in the intersection of these lists were used to define the set of "cold standard" (COS) upregulated genes. Receiver-OperatorCharacteristic (ROC) curves (which have been shown to be an effective method for evaluating gene expression data [55]) were generated for these COS-upregulated genes [54] by distinguishing each ranked gene as either a true positive or a false positive (Figure 4). A larger area under an ROC curve indicates that more COS-upregulated genes are identified. The line at which the number of true positives is equal to the number of false positives is indicated in Figure 4, and only the data above this line are considered biologically relevant. By ranking genes by their maximum fold change values in the treatment-frequency dataset, $52.6 \%(159 / 302)$ of known COS upregulated genes can be identified, compared to only $21.2 \%(64 / 302)$ in the original dataset (Table 1) [54]. This difference may be explained by the disruptions contributed by the clock-frequency influences and the noise-frequency influences, which are present in the original dataset. This shows that more COSupregulated genes can be identified by ranking by the maximum fold change in the treatment-frequency dataset compared to the original dataset.

Principal component analysis (PCA) is a linear component composition method that has been applied to summarize different gene expression influences under different conditions, and consequently has been used for differential gene expression studies in microarray datasets [56]. PCA was performed on the original dataset (Additional file 1: Figure S2A), and the Euclidean distance from the bottom-left of the PCA plot of the first and second component was used to rank the genes, allowing for the construction of an ROC curve based on this data (Figure 4). These data show that only $13.9 \%$ (42/302) of the cold upregulated genes can be identified in the original PCA plot. The first PCA components of

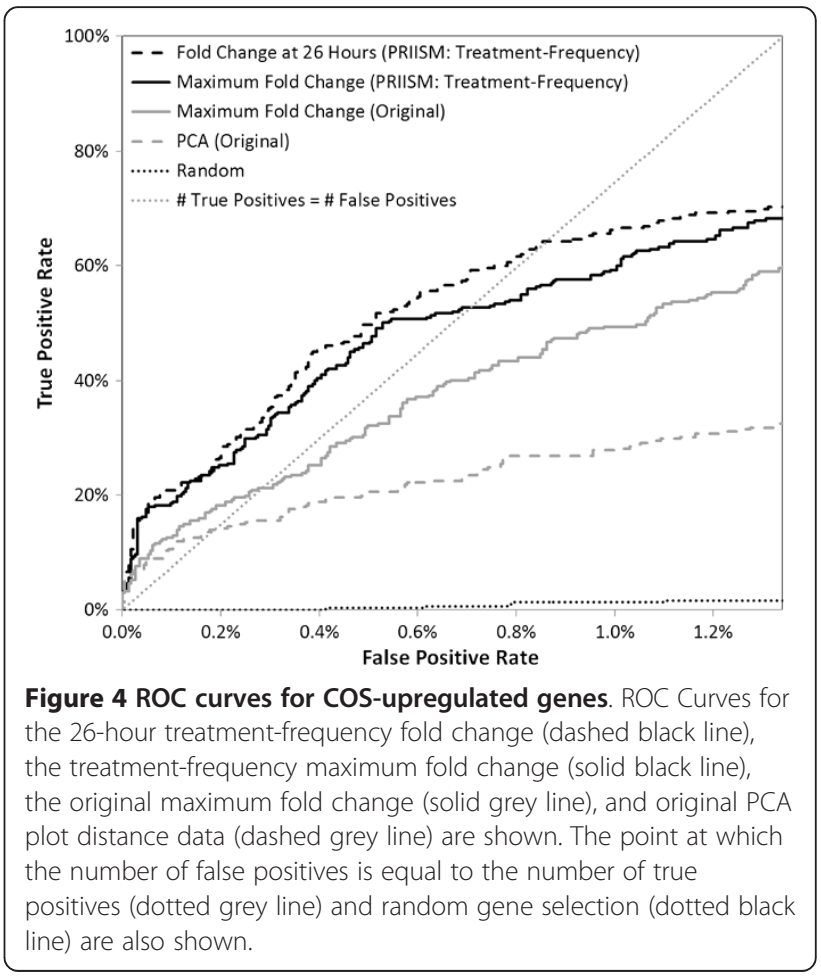




\begin{tabular}{|c|c|c|c|c|c|}
\hline \multirow[t]{2}{*}{ Statistic } & \multicolumn{2}{|c|}{ Original Data } & \multicolumn{3}{|c|}{ Treatment-Frequency Data } \\
\hline & $\begin{array}{l}\text { Maximum } \\
\text { Fold } \\
\text { Change }\end{array}$ & $\begin{array}{c}\text { PCA } \\
\text { Distance }\end{array}$ & $\begin{array}{l}\text { Maximum } \\
\text { Fold } \\
\text { Change }\end{array}$ & $\begin{array}{c}\text { PCA } \\
\text { Distance }\end{array}$ & $\begin{array}{c}\text { Fold } \\
\text { Change at } \\
26 \text { Hours }\end{array}$ \\
\hline $\begin{array}{l}\text { Recall when true } \\
\text { positives = } \\
\text { false positives }\end{array}$ & $21.2 \%$ & $13.9 \%$ & $52.6 \%$ & $46.0 \%$ & $64.2 \%$ \\
\hline $\begin{array}{c}\text { Number of true } \\
\text { positives identified } \\
\text { when true } \\
\text { positives = } \\
\text { false positives } \\
\text { (Out of } 302 \text { true } \\
\text { positives) }\end{array}$ & 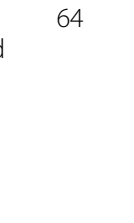 & 42 & 159 & 139 & 194 \\
\hline
\end{tabular}

the treatment-frequency data and the clock-frequency data were also plotted (Additional file 1: Figure S2B) and ranking based on Euclidean distance from the bottomright was able to identify $46.0 \%(139 / 302)$ of the COSupregulated genes.

These results showed that, in both maximum fold change and PCA analyses, the ranked treatmentfrequency fold change analyses produce fewer false positives than the original methodology by distinguishing more COS-upregulated genes (Table 1).

\section{The identification of important gene regulation timepoints using PRIISM}

In the previous section, it was shown that gene discovery in the treatment-frequency data produced by PRIISM constantly outperforms the same analyses on the original data. Although these approaches are useful for poorly studied treatment responses, a knowledge-based approach may be used to identify more treatment-response genes with a lower false positive rate.

Cold treatments have been shown to induce the expression of the transcription factors C-repeat/DRE Binding Factor genes CBF1, CBF2 and CBF3 [57], which are induced in parallel with the cold transcription factors RAV1 and ZAT12 [50]. Some of the important targets of $C B F$ transcription factors include Cold-Responsive (COR) genes COR15A, COR15B, COR47, and COR78 $[20,50,58,59]$. All of the cold transcription factors and targets included in these lists have also been shown to be gated by the circadian clock, making them ideal for evaluating PRIISM's ability to remove clock-frequency influences $[6,20,23]$.

In the treatment-frequency data, a peak in the fold change patterns can be observed in the well-studied cold response transcription factors and cold regulated (COR) response genes at the start of the first night (at approximately 26 hours) (Figure 5C, 5D). The peaks of the transcription factors can be seen to occur before the peaks of their target genes, as is expected for a TF-target relationship. By contrast, these peaks are not apparent in the original fold change data (Figure 5A, 5B). For this reason, an ROC curve was computed using the fold change value at 26 hours in the treatment-frequency fold change data (Figure 4, Table 1). Table 1 shows that $194 / 302(64.2 \%)$ of the true-positive COS-upregulated genes can be identified with a $50 \%$ false positive rate in the treatment-frequency 26-hour fold change data, compared to only $64 / 302(21.2 \%)$ for the maximum fold change in original data and 42/302 (13.9\%) for the PCA plot of the original data.

This data shows that the fold change value at 26 hours in the treatment-frequency data is the best predictor of whether a gene is involved in adaptive cold response. The top 25 ranked genes based on fold changes at 26 hours in the treatment-frequency dataset are shown in Table 2. Included in this table is the "Cold Upregulation Category" for each gene, which indicates whether a gene was upregulated in the cold when plants were grown in soil ("Soil"), on agar plates ("Plate"), on both growth mediums ("COS"), or on neither ("Novel") in Vogel et al's study [54]. In this table, $22 / 25$ of the genes belonged to the COS group, 2 belonged to the "Plate" group, and 1 belonged to the "Soil" group, suggesting that the PRIISM method has successfully identified known coldregulation genes [54]. Table 3 shows the top 25 ranked genes which were not part of the COS-upregulated gene list in Vogel et al (2005) [54]. 10/25 of the genes in this list belonged to the "Soil" group, 9 belonged to the "Plate" group, and 6 were novel genes not identified in Vogel et al's study [54]. All of the novel genes (and all but one of the 25 genes in this list) have been previously identified as being involved in cold response in other studies, suggesting that PRIISM has identified a list of very important cold-response genes (See "Comments" column in Table 8).

The results of a case study on ATGolS3 (AT1G09350), the gene with the largest fold change in the treatmentfrequency data at 26 hours are shown in Figure 6. The logged original gene expression curve under warm conditions has a minimum expression level of approximately 6 , which is reflected by a flat treatment-frequency expression curve with a nearly constant value of 6 (Figure 6A). The rhythmic pattern of the original data in warm conditions is captured in the clock-frequency gene expression curve, and the sharp peaks and sudden changes in slope are captured in the noise-frequency curve (Figure 6A). The original gene expression data under cold conditions peaks quite strongly during the first night but retains some cyclical expression. The PRIISM-processed gene expression data shows that the treatment-frequency gene expression is constantly higher in the cold, with a peak at 26 hours, while the clock-frequency gene expression data is only marginally 


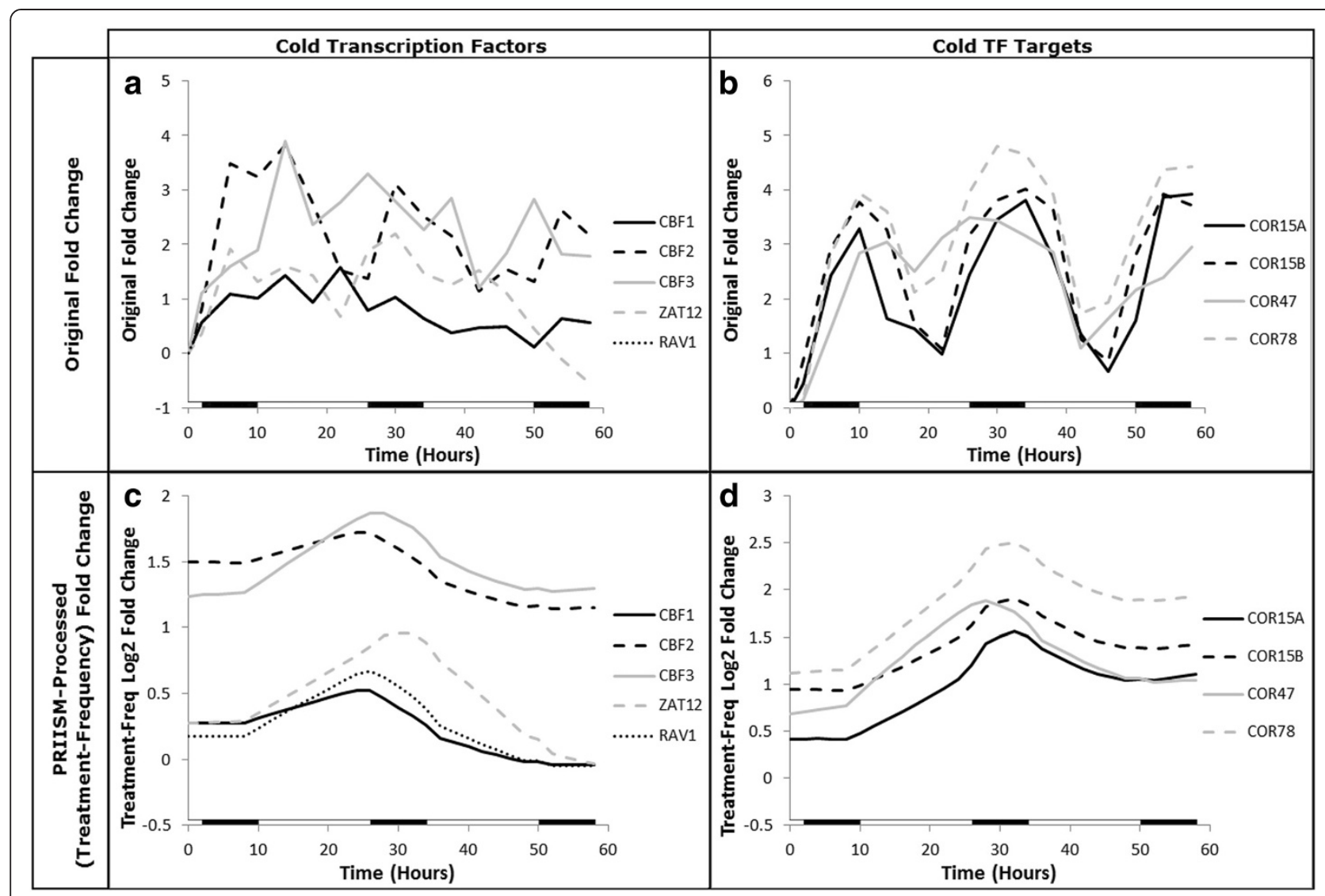

Figure 5 Fold change patterns of cold transcription factors and target genes before and after PRIISM processing. The original fold change patterns for important cold transcription factors (A) and some of their important target (COR) genes (B) are shown, along with their the treatment-frequency fold change patterns for the same genes (C \& D). Thin, dashed vertical lines are used to indicate the 26 hour position on each graph.

increased, but is increased more in the first day than in the second day (Figure 6B, 6C). The fold change graph shown in Figure $6 \mathrm{C}$ indicates that most of the increase in gene expression is due to treatment-frequency influences for this gene, but the clock-frequency influences upregulate the gene more strongly early in the cold treatment. The noise-frequency fold change pattern matches many of the sharp peaks and valleys in the original fold change pattern, suggesting that much of the noise has indeed been removed (Figure 6C).

To test the statistical significance of PRIISM's ability to discover treatment-response genes, $\mathrm{P}$-values were calculated using a Z-test for both the maximum fold change from the original dataset and the fold change values at 26 hours in the treatment-frequency dataset. Figure 7 shows the number of genes that were found to be significant ( $P$ value $<=0.05$ ) in these tests, and how many belonged to the COS-upregulated gene list from Vogel et al [54]. Out of the 161 genes significant in the treatment-frequency data at 26 hours, 98 of them (60.9\%) were COS upregulated genes, compared to 154 out of $379(39.3 \%)$ for the original dataset.

\section{Clock-frequency data analysis}

The clock vectors calculated by Equation 3 under both warm and cold conditions for each of the time frames are shown in Figure 8. The difference between the length and the shape of the warm and cold vectors indicates the circadian rhythm disruption caused by the cold stress. Figure 8A shows drastically different frequency profiles for the warm and cold conditions, caused by an abrupt phase shift in the expression data. The clock genes continue to have disrupted frequencies in the second time frame (Figure 8B), but appear to return to normal oscillating frequencies, possibly with different phases, in time frames 3 and 4 (Figure 8C, 8D).

To study whether the clock-frequency data produced by PRIISM successfully isolated cyclic clock influences from treatment-response influences, the clock-frequency gene expression patterns of eight well-studied cold response genes were matched with standard clock patterns according to the pattern-matching algorithm HAYSTACK [26]. This algorithm (the key component of The Diurnal Project) utilizes a model-based pattern matching algorithm to calculate the phase and cyclic pattern type 
Table 2 Genes ranked based on their treatment-frequency fold change values at $\mathbf{2 6}$ hours

\begin{tabular}{|c|c|c|c|}
\hline Rank & Annotation & $\begin{array}{l}\text { P-Value (Treatment-Frequency Fold } \\
\text { Change, } 26 \text { Hours) }\end{array}$ & $\begin{array}{l}\text { Cold Upregulation } \\
\text { Category* [54] }\end{array}$ \\
\hline 1 & AT1G09350: Arabidopsis thaliana Galactinol Synthase 3 (AtGolS3) & $3.97 \mathrm{E}-31$ & $\cos$ \\
\hline 2 & AT4G14690: Early Light-Inducible Protein 2 (ELIP2) & $3.18 \mathrm{E}-28$ & $\cos$ \\
\hline 3 & AT4G12470: Azelaic Acid Induced 1 (AZI1) & $1.23 \mathrm{E}-25$ & $\cos$ \\
\hline 4 & AT3G50970: Low Temperature-Induced 30 (LTI30) & $3.62 \mathrm{E}-22$ & $\cos$ \\
\hline 5 & AT1G16850: Unknown protein & $7.38 \mathrm{E}-22$ & $\cos$ \\
\hline 6 & AT3G22840: Early Light-Inducible Protein 1 (ELIP1) & $8.66 \mathrm{E}-21$ & $\cos$ \\
\hline 7 & AT1G51090: Heavy-metal-associated domain-containing & $1.41 \mathrm{E}-16$ & $\cos$ \\
\hline 8 & $\begin{array}{c}\text { AT3G55580: Regulator of chromosome condensation (RCC1) family } \\
\text { protein }\end{array}$ & $3.62 \mathrm{E}-16$ & $\cos$ \\
\hline 9 & AT5G25110: CIPK25 (CBL-Interacting Protein Kinase 25) & $1.13 \mathrm{E}-13$ & $\cos$ \\
\hline 10 & AT5G52310: COR78 (Cold Regulated 78) & $3.25 \mathrm{E}-13$ & $\cos$ \\
\hline 11 & $\begin{array}{c}\text { AT1G02820: late embryogenesis abundant } 3 \text { family protein/LEA3 family } \\
\text { protein }\end{array}$ & $3.29 \mathrm{E}-13$ & Soil \\
\hline 12 & AT4G30830: similar to unknown protein (AT2G24140.1) & $5.57 \mathrm{E}-13$ & $\cos$ \\
\hline 13 & AT2G23910: Cinnamoyl-CoA reductase-related & 9.97E-13 & Plate \\
\hline 14 & $\begin{array}{l}\text { AT1G48100: Glycoside hydrolase family } 28 \text { protein/polygalacturonase } \\
\text { (pectinase) family protein }\end{array}$ & $1.93 \mathrm{E}-12$ & $\cos$ \\
\hline 15 & AT5G17030: UDP-Glucosyl Transferase 78D3 (UGT78D3) & 3.07E-12 & $\cos$ \\
\hline 16 & AT4G33070: Pyruvate decarboxylase, putative & $3.43 \mathrm{E}-12$ & $\cos$ \\
\hline 17 & AT3G17130: Invertase/pectin methylesterase inhibitor family protein & $4.21 \mathrm{E}-11$ & $\cos$ \\
\hline 18 & AT1G11210: Similar to unknown protein (TAIR:AT1G11220.1) & $1.06 \mathrm{E}-10$ & $\cos$ \\
\hline 19 & $\begin{array}{l}\text { AT1G62570: Flavin-monooxygenase Glucosinolates-Oxygenase } 4 \text { (FMO } \\
\text { GS-OX4) }\end{array}$ & $3.24 \mathrm{E}-10$ & $\cos$ \\
\hline 20 & AT2G16890: UDP-glucoronosyl/UDP-glucosyl transferase family protein & $5.52 \mathrm{E}-10$ & $\cos$ \\
\hline 21 & $\begin{array}{c}\text { AT4G25480: Dehydration response element B1A (DREB1A); C-Repeat } \\
\text { Binding Factor } 3(C B F 3)\end{array}$ & $6.1 \mathrm{E}-10$ & $\cos$ \\
\hline 22 & AT1G20440: Cold-Regulated 47 (COR47); (RD17) & $1.08 \mathrm{E}-09$ & $\cos$ \\
\hline 23 & AT1G61800: Glucose-6-Phosphate/Phosphate Translocator 2 (GPT2) & 1.37E-09 & Plate \\
\hline 24 & AT4G17550: Transporter-related & $1.52 \mathrm{E}-09$ & $\cos$ \\
\hline 25 & AT1G62710: Beta Vacuolar Processing Enzyme (BETA-VPE) & $5.78 \mathrm{E}-09$ & $\cos$ \\
\hline
\end{tabular}

*" Cold Upregulation Category" indicates whether a gene was upregulated in the cold when plants were grown in soil ("Soil"), on agar plates ("Plate"), on both growth mediums ("COS"), or on neither ("Novel") in Vogel et al's study [54].

for each gene in a dataset, and also calculates the correlation of each gene to the closest model, which can be used as an indication of how strong the clock influence is on the gene [26]. HAYSTACK provides T-test P-values indicating the probability that an input pattern matches a gene expression model, and provides several types of cyclic clock pattern models to use for comparison [26]. This analysis included the COR genes which have been shown to be under circadian clock control under warm conditions, but gated by cold transcription factors (including the CBF genes) under cold conditions [20]. The results in Table 4 indicate that the $\mathrm{P}$ values for the clockfrequency gene expression data from PRIISM are substantially lower than the original data (under both warm and cold conditions), often by several orders of magnitude, demonstrating enrichment of clock-frequency gene expression in this data.Note that the remaining portion of the spectrum of the clock-frequency components is simply discarded in PRIISM. In our future work, it will be interesting to further test whether feeding it into the treatmentfrequency component will construct more precise results.

\section{Conclusions}

Circadian rhythm pathways influence the expression patterns of as much as $31 \%$ of the Arabidopsis genome through complicated interaction pathways, and have been found to be significantly disrupted by biotic and abiotic stress treatments, complicating treatmentresponse gene discovery methods due to clock pattern mismatches in the fold change statistic. The PRIISM 
Table 3 The top 25 ranked non-COS genes based on treatment-frequency fold change values at 26 hours

\begin{tabular}{|c|c|c|c|c|}
\hline Rank & Annotation & Comments & $\begin{array}{l}\text { P Value (Treatment- } \\
\text { Frequency Fold } \\
\text { Change, } 26 \text { Hours) }\end{array}$ & $\begin{array}{l}\text { Cold } \\
\text { Upregulation } \\
\text { Category* } \\
\text { [54] }\end{array}$ \\
\hline 11 & $\begin{array}{l}\text { AT1G02820: Late embryogenesis abundant } 3 \\
\text { family protein/LEA3 family protein }\end{array}$ & $\begin{array}{l}\text { LEA family proteins are associated with dehydration } \\
\text { stress (and therefore cold) and general environmental } \\
\text { stress in plants, and desiccation tolerance in other } \\
\text { organisms including bacteria [60]. Cold response genes } \\
\text { COR15A, COR15B and COR47 are classified as LEA genes. } \\
\text { Although not to the same degree as the COR genes, } \\
\text { expression of this gene was upregulated by cold } \\
\text { according to quantitative RT-PCR [60] }\end{array}$ & $3.29 \mathrm{E}-13$ & Soil \\
\hline 13 & AT2G23910: Cinnamoyl-CoA reductase-related & $\begin{array}{l}\text { Implicated in the biosynthesis of phenylpropanoids } \\
\text { [61,62], which contribute to many different plant } \\
\text { responses to biotic and abiotic stress/challenge [63] }\end{array}$ & 9.97E-13 & Plate \\
\hline 23 & $\begin{array}{c}\text { AT1G61800: GPT2 (Glucose-6-Phosphate } \\
\text { Translocator 2) }\end{array}$ & $\begin{array}{l}\text { A gpt2 mutant shows an impairment in photosynthetic } \\
\text { acclimation in response to shifts to high irradiance light, } \\
\text { which can be exacerbated under cold conditions [64] }\end{array}$ & 1.37E-09 & Plate \\
\hline 29 & $\begin{array}{l}\text { AT5G06760: Late embryogenesis abundant group } \\
1 \text { (LEA group 1) domain-containing protein }\end{array}$ & $\begin{array}{c}\text { Similar to other LEA above (AT1G02820), expression of } \\
\text { this gene is upregulated by cold according to } \\
\text { quantitative RT-PCR [60] }\end{array}$ & 1.86E-08 & Soil \\
\hline 37 & $\begin{array}{l}\text { AT3G51240: F3H; TT6 (Flavanone 3-Hydroxylase; } \\
\text { Transparent Testa 6) }\end{array}$ & Implicated in freezing stress response [65] & 7.07E-08 & Plate \\
\hline 50 & $\begin{array}{l}\text { AT1G60190: Armadillo/beta-catenin repeat family/ } \\
\text { U-box domain-containing }\end{array}$ & & $1.92 \mathrm{E}-06$ & Soil \\
\hline 53 & $\begin{array}{l}\text { AT5G24120: SIGE/SIG5 (RNA polymerase sigma } \\
\text { subunit E); DNA binding/DNA-directed RNA } \\
\text { polymerase/sigma/transcription factor }\end{array}$ & $\begin{array}{c}\text { Regulated in blue light by cryptochromes and involved } \\
\text { in light-dependent regulation of the photosynthetic } \\
\text { apparatus [66]. In a separate study shown to be essential } \\
\text { for Arabidopsis [67] }\end{array}$ & $3.24 \mathrm{E}-06$ & Soil \\
\hline 55 & $\begin{array}{c}\text { AT1G10370: ATGSTU17/ERD9/(Early-Responsive to } \\
\text { Dehydration 9) }\end{array}$ & Dehydration responsive [68] & 4.43E-06 & Plate \\
\hline 57 & AT1G32900: Starch synthase, putative & $\begin{array}{l}\text { Identified in a study on light/cold interactions [69]. } \\
\text { Upregulated by cold generally, but upregulated more } \\
\text { under cold/light conditions than cold/dark }\end{array}$ & $6.47 \mathrm{E}-06$ & Novel \\
\hline 60 & $\begin{array}{l}\text { AT4G33905: Peroxisomal membrane protein } \\
\qquad 22 \mathrm{kDa} \text {, putative }\end{array}$ & Upregulated by stress, including cold treatment [70] & $7.71 \mathrm{E}-06$ & Novel \\
\hline 61 & AT1G01520: Myb family transcription factor & $\begin{array}{l}\text { Upregulated in mutant that has improved freezing } \\
\text { tolerance (i.e. esk1 mutant) [71]. }\end{array}$ & $1.63 \mathrm{E}-05$ & Novel \\
\hline 63 & AT5G57760: Unknown & & $1.95 \mathrm{E}-05$ & Plate \\
\hline 70 & AT5G14760: AO (L-aspartate oxidase) & $\begin{array}{l}\text { Involved in the synthesis of NAD [72], which is } \\
\text { phosphorylated by cold in other plants [73] }\end{array}$ & 4.96E-05 & Novel \\
\hline 71 & AT1G10585: Transcription factor & $\begin{array}{c}\text { Upregulated under conditions associated with oxidative } \\
\text { stress/high light [74] }\end{array}$ & $5.66 \mathrm{E}-05$ & Soil \\
\hline 72 & AT5G07010: Sulfotransferase family & Jasmonate responsive [68] & 5.95E-05 & Soil \\
\hline 75 & AT2G22590: Glycosyltransferase family protein & $\begin{array}{l}\text { In the same gene family as UGT91A1, (a target of a TF } \\
\text { that regulates flavonol synthesis), and is thus proposed } \\
\text { to impact flavonol biosynthesis, which is a product } \\
\text { associated with cold response }[75,76]\end{array}$ & $6.55 \mathrm{E}-05$ & Plate \\
\hline 76 & $\begin{array}{l}\text { AT3G17609: HYH (HY5-Homolog); DNA binding/ } \\
\text { transcription factor }\end{array}$ & $\begin{array}{l}\text { Involved in phyB signaling [77]; Required for low } \\
\text { temperature-induced anthocyanin accumulation [78] }\end{array}$ & $6.78 \mathrm{E}-05$ & Novel \\
\hline 81 & $\begin{array}{l}\text { AT1G17170: ATGSTU24 (Arabidopsis thaliana } \\
\text { Glutathione S-Transferase (TAU) 24) }\end{array}$ & $\begin{array}{c}\text { Member of the Glutathione S-transferase family (involved } \\
\text { in flavonoid synthesis and general abiotic stress } \\
\text { response) [79] }\end{array}$ & 0.000123 & Soil \\
\hline 82 & $\begin{array}{c}\text { AT5G07990: TT7 (Transparent Testa 7); flavonoid } \\
\text { 3'-monooxygenase }\end{array}$ & $\begin{array}{c}\text { Flavonoid biosynthesis protein, which is a product } \\
\text { associated with cold response }[68,76]\end{array}$ & 0.000125 & Plate \\
\hline 83 & $\begin{array}{l}\text { AT3G55940: Phosphoinositide-specific } \\
\text { phospholipase C, putative }\end{array}$ & $\begin{array}{c}\text { Phospholipase } C \text { genes, to which this is related, have } \\
\text { been associated with responses to stress in Arabidopsis } \\
\text { [80] }\end{array}$ & 0.000142 & Plate \\
\hline
\end{tabular}




\section{Table 3 The top 25 ranked non-COS genes based on treatment-frequency fold change values at 26 hours (Continued)}

\begin{tabular}{|c|c|c|c|c|}
\hline 84 & $\begin{array}{l}\text { AT3G21560: UGT84A2; UDP-glycosyltransferase/ } \\
\text { sinapate 1-glucosyltransferase }\end{array}$ & $\begin{array}{l}\text { Upregulated by cold via the phospholipase D-dependent } \\
\text { phosphatidic acid production [81] }\end{array}$ & 0.000145 & Plate \\
\hline 85 & AT5G49480: ATCP1 (CA2+-Binding Protein 1) & $\begin{array}{l}\text { A "cold regulated signaling gene" that is altered in an } \\
\text { ice1 mutant background (ICE1 is a cold/freezing related } \\
\text { TF) [51]. Regulation altered under drought conditions } \\
\text { [82]. Also (like UGT84A2, above) upregulated by cold via } \\
\text { phospholipase D-dependent phosphatidic acid } \\
\text { production [81] }\end{array}$ & 0.000168 & Soil \\
\hline 86 & AT5G44110: POP1 & $\begin{array}{l}\text { Shown to be upregulated by cold in supplemental table } \\
\text { of [83]. Response to Red and Far-Red light via phyA [84]. } \\
\text { Also a target of HY5 [85], which is a transcription factor } \\
\text { in light signaling/responsiveness, but also shown to be } \\
\text { important for cold dependent anthocyanin accumulation } \\
\text { together with HYH (above) [78] }\end{array}$ & 0.00017 & Soil \\
\hline 87 & $\begin{array}{c}\text { AT5G36910: THI2.2 (Thionin 2.2); toxin receptor } \\
\text { binding }\end{array}$ & $\begin{array}{c}\text { Downregulated under high temperature stress [86], } \\
\text { associated with jasmonic acid/salicylic acid signalling [87] } \\
\text { and target of FAR1 and FHY3, which function in phyA } \\
\text { signaling [88] }\end{array}$ & 0.000174 & Novel \\
\hline 88 & $\begin{array}{l}\text { AT2G31380: STH1 (salt tolerance homologue); } \\
\text { transcription factor/zinc ion binding, also } \\
\text { previously denoted ZF3 }\end{array}$ & $\begin{array}{l}\text { Like POP1 above, shown to be upregulated by cold in } \\
\text { supplemental table of [83]. Circadian-controlled zinc } \\
\text { finger gene with role in light signaling [89]. Additional } \\
\text { evidence for role in light signaling and regulation by } \\
\text { phytochrome }[90,91] \text {, and like THI2 (above), target of } \\
\text { FAR1 and FHY3, which function in phyA signaling [88] }\end{array}$ & 0.000176 & Soil \\
\hline
\end{tabular}

*" Cold Upregulation Category" indicates whether a gene was upregulated in the cold when plants were grown in soil ("Soil"), on agar plates ("Plate"), on both growth mediums ("COS"), or on neither ("Novel") in Vogel et al's study [54].

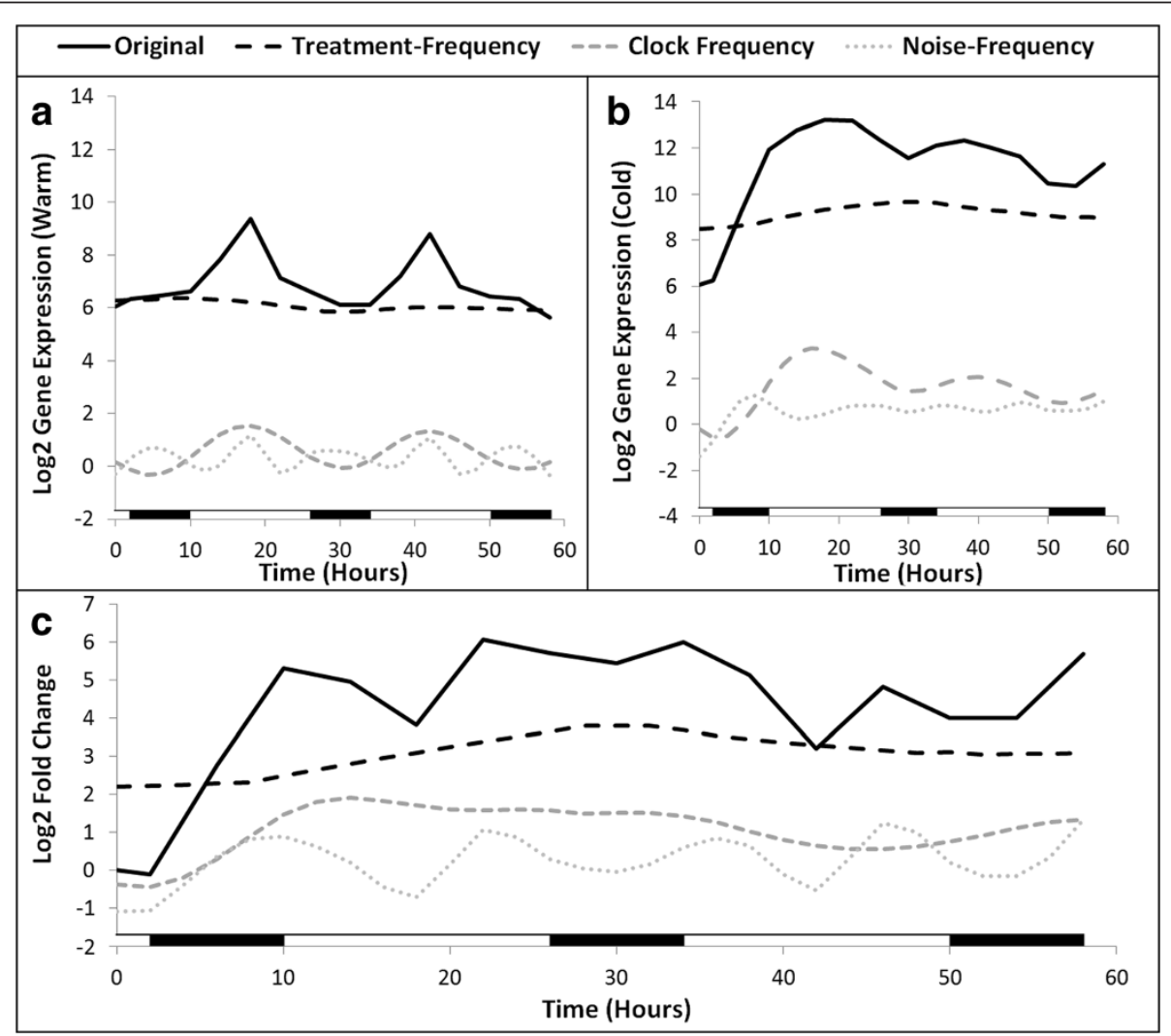

Figure 6 A case study examining PRIISM output gene expression and fold change data. The fold change patterns (A), warm gene expression patterns (B) and cold gene expression patterns (C) for the original and PRIISM-processed data for AtgolS3 (AT1G09350), the most highly upregulated gene in response to cold at 26 hours in the treatment-frequency data. 


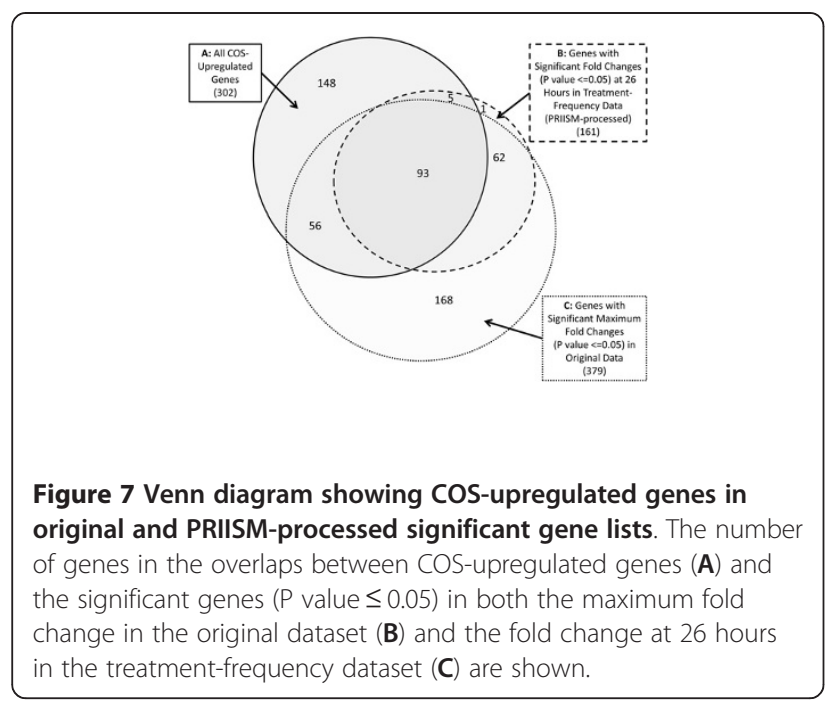

algorithm outlined in this paper is designed to separate pattern changes induced by different forces, including treatment pathways and circadian clock rhythm disruptions. By applying PRIISM on a cold-response dataset, we systematically evaluated our method using maximum fold change and PCA analyses. The results of this study showed that the ranked treatment-frequency fold change
Table 4 A comparison of the clock patterns between PRIISM-processed and original gene expression data

\begin{tabular}{|c|c|c|c|c|c|}
\hline \multirow[t]{2}{*}{$\begin{array}{l}\text { Gene } \\
\text { Name }\end{array}$} & \multirow[t]{2}{*}{ AGI Number } & \multicolumn{2}{|c|}{$\begin{array}{c}\text { P-values for Warm } \\
\text { Gene Expression } \\
\text { Data }\end{array}$} & \multicolumn{2}{|c|}{$\begin{array}{c}\text { P-values for Cold } \\
\text { Gene Expression } \\
\text { Data }\end{array}$} \\
\hline & & Original & $\begin{array}{l}\text { Clock- } \\
\text { Frequency } \\
\text { (PRIISM) }\end{array}$ & Original & $\begin{array}{l}\text { Clock- } \\
\text { Frequency } \\
\text { (PRIISM) }\end{array}$ \\
\hline COR15A & AT2G42540 & $5.6 \mathrm{E}-17$ & 0 & 0.125 & 0.039 \\
\hline COR15B & AT2G42530 & 0 & 0 & 0.038 & 4.3E-03 \\
\hline COR47 & AT1G20440 & 4.7E-09 & $1.8 \mathrm{E}-13$ & 0.012 & $3.8 \mathrm{E}-03$ \\
\hline COR78 & AT5G52310 & 0 & 0 & 0.013 & 2.3E-03 \\
\hline$C B F 1$ & AT4G25490 & 5.0E-07 & 7.2E-08 & 4.5E-04 & $3.8 \mathrm{E}-05$ \\
\hline$C B F 2$ & AT4G25470 & $3.9 \mathrm{E}-06$ & $1.6 \mathrm{E}-13$ & 3.2E-08 & 2.2E-09 \\
\hline$C B F 3$ & AT4G25480 & $5.5 E-14$ & $5.6 \mathrm{E}-17$ & 2.6E-07 & $5.0 \mathrm{E}-10$ \\
\hline RAV1 & AT1G13260 & $1.8 \mathrm{E}-06$ & $3.0 \mathrm{E}-10$ & 7.4E-05 & $2.8 \mathrm{E}-04$ \\
\hline ZAT12 & AT5G59820 & $3.4 \mathrm{E}-03$ & 4.9E-05 & 1.4E-04 & 1.9E-05 \\
\hline
\end{tabular}

P-values (calculated using the $T$-test HAYSTACK function) indicate the correlation of the gene expression patterns of well-studied cold-responsive genes to pre-defined cyclic clock patterns.

analyses produce fewer false positives than the original methodology, and the 26 hour timepoint in the PRIISM produced dataset was the best statistic for distinguishing the most known cold-response genes. In addition,

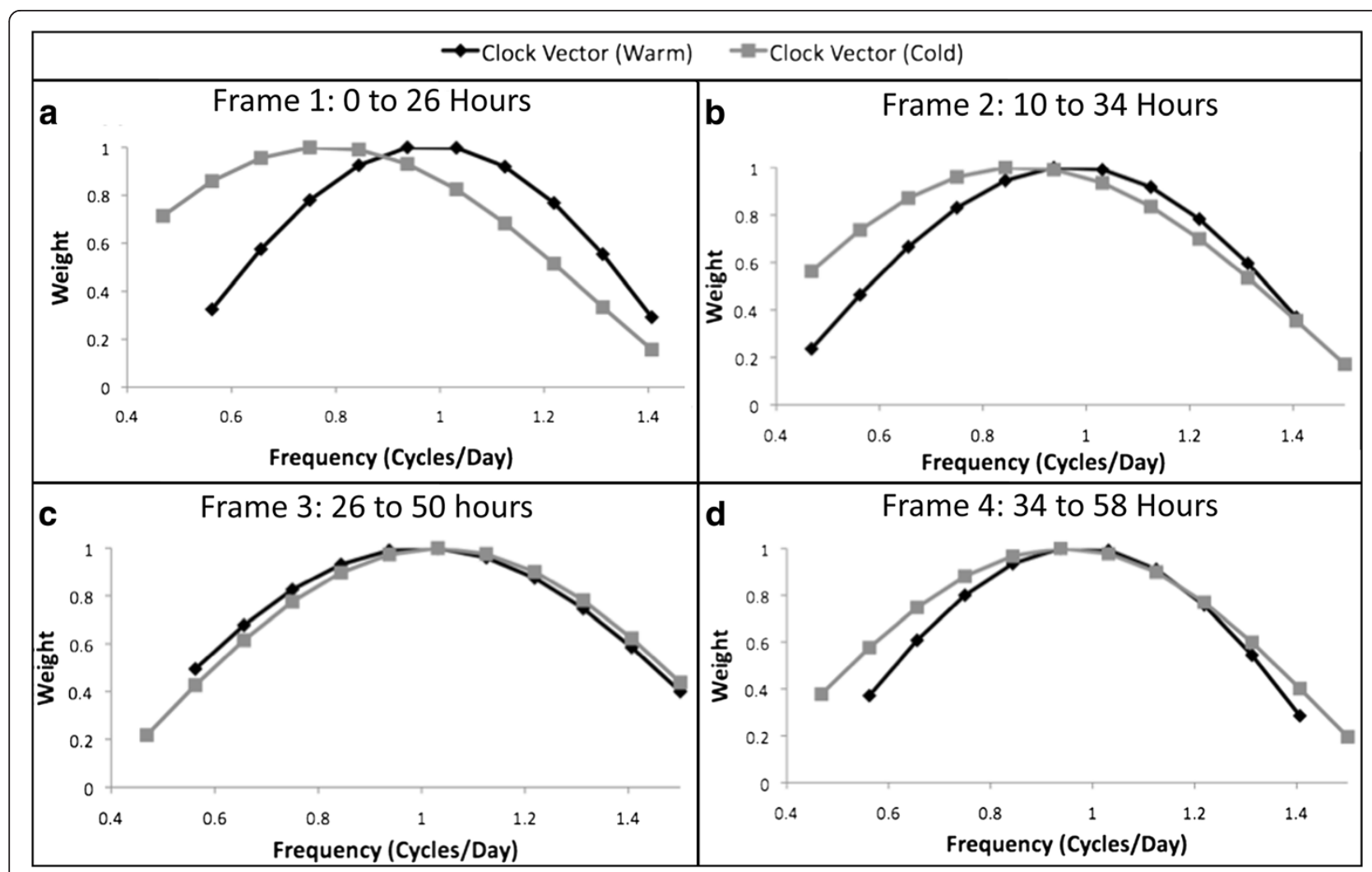

Figure 8 Clock vectors under warm and cold conditions. 
PRIISM also provides gene expression data which represent only circadian clock influences, and may be useful for circadian clock studies. In fact, any existing analysis approach on gene expression data can utilize PRIISM to separate circadian-influenced changes in gene expression. In conclusion, PRIISM is a novel approach for overcoming the problem of circadian disruptions from stress treatments on plants. PRIISM can be integrated with any existing analysis approach on gene expression data to separate circadian-influenced changes in gene expression, and it can be extended to apply to any organism with regular oscillations in gene expression patterns across a large portion of the genome. In future work, we will apply the discrete wavelet transforms (DWT) on higher resolution datasets in order to further enhance the ability of PRIISM to distinguish circadian clock disruption influences from treatment-response pathway influences.

\section{Additional file}

\section{Additional file 1: Figure S1: Time frames used to generate FFT} results. Frame sizes and positions are shown in $(\mathbf{A})$ and the contribution of each frame to the weighted average at each timepoint is shown in (B). Figure S2: Principal Component Analysis (PCA) Plots. Principal component analysis (PCA) plots for the original data (A) and the first components of the clock-frequency and treatment-frequency data (B) are shown. COS-upregulated genes are shown in black circles, COSdownregulated genes (which are not analyzed in detail here) are shown in white diamonds and all other genes are shown as grey dots. Figure S3: The original, mean-shifted, PRIISM-reconstructed and Butterworth-filter reconstructed gene expression patterns of AtGolS3. (A) The original (black) and mean-shifted (grey) expression values of AtGolS3. (B) Comparison between the treatment-frequencyreconstructed gene expression patterns for AtGolS3 using PRIISM (Black line) and using a fifth-order Butterworth low-pass filter (grey line). Figure S4: The frequency spectra of the original, the PRIISM-reconstructed and the Butterworth-filter reconstructed gene expression patterns of AtGolS3. (A) The Frequency Spectrum of the original gene expression pattern of AtGolS3. (B) Comparison of the frequency spectra of AtGolS3 after processing using PRIISM (white circles) and the fifth-order Butterworth low-pass filter (grey diamonds). The original treatmentfrequency spectrum of AtGolS3 is also shown (red bars). Figure S5: The Bode plot of a fifth-order Butterworth low-pass filter for AtGolS3.

\section{Competing interests}

The authors declare that they have no competing interest.

\section{Acknowledgements}

We thank Dr. Michael Thomashow and Dr. Eva Farré for their feedback and helpful advice. This project has been funded by the U.S. Department of Energy (Chemical Sciences, Geosciences and Biosciences Division, grant no. DE-FG02-91ER20021 to J.C. and B.L.M), The National Science Foundation (grant no. MCB-0919100 to B.L.M.), the Natural Sciences and Engineering Research Council of Canada (NSERC) through a Post-Graduate Scholarship to B.R. and NSERC Collaborative Research and Development grant to W.Q., and Ontario Research Chair funding to W.Q.

\section{Author details}

${ }^{1}$ Biorefining Research Initiative and Department of Biology, Lakehead University, 955 Oliver Road, Thunder Bay, ON P7B 5E1, Canada. ${ }^{2}$ MSU-DOE Plant Research Laboratory, Plant Biology Laboratories, Michigan State University, 612 Wilson Road, Rm. 106, East Lansing, Ml 48824, USA

${ }^{3}$ Department of Biochemistry and Molecular Biology, Michigan State
University, 603 Wilson Road, Room 212, East Lansing, MI48824, USA. ${ }^{4}$ Department of Computer Sciences and Engineering, Michigan State University, 3115 Engineering Building, East Lansing, MI 48824, USA.

\section{Authors' Contributions}

JC, YJ, BR conceived and designed the algorithm. YJ designed MATLAB code for algorithm. BR performed pre-processing and post-processing of data. BR and YJ wrote the manuscript, which was edited by JC, BM, SO and WQ. BM and $\mathrm{SO}$ also provided biological knowledge and research of circadian and cold response genes. All authors read and approved the final manuscript.

Received: 31 October 2011 Accepted: 15 June 2012

Published: 15 June 2012

\section{References}

1. Cui $X$, Churchill GA: Statistical tests for differential expression in CDNA microarray experiments. Genome Biol 2003, 4:210.

2. Adams S, Carre IA: Downstream of the plant circadian clock: output pathways for the control of physiology and development. Essays Biochem 2011, 49:53-69.

3. Bilgin DD, Zavala JA, Zhu J, Clough SJ, Ort DR, DeLucia EH: Biotic stress globally downregulates photosynthesis genes. Plant Cell Environ 2010, 33:1597-1613.

4. Chaves MM, Flexas J, Pinheiro C: Photosynthesis under drought and salt stress: regulation mechanisms from whole plant to cell. Ann Bot 2009, 103:551-560.

5. Michael TP, Mockler TC, Breton G, McEntee C, Byer A, Trout JD, Hazen SP, Shen R, Priest HD, Sullivan CM, et al: Network discovery pipeline elucidates conserved time-of-day-specific cis-regulatory modules. PLoS Genet 2008, 4:e14.

6. Bieniawska Z, Espinoza C, Schlereth A, Sulpice R, Hincha DK, Hannah MA: Disruption of the Arabidopsis circadian clock is responsible for extensive variation in the cold-responsive transcriptome. Plant Physiol 2008, 147:263-279.

7. Espinoza C, Degenkolbe T, Caldana C, Zuther E, Leisse A, Willmitzer L, Hincha DK, Hannah MA: Interaction with diurnal and circadian regulation results in dynamic metabolic and transcriptional changes during cold acclimation in Arabidopsis. PLoS One 2010, 5:e14101.

8. Nakamichi N, Kusano M, Fukushima A, Kita M, Ito S, Yamashino T, Saito K, Sakakibara H, Mizuno T: Transcript profiling of an Arabidopsis PSEUDO RESPONSE REGULATOR arrhythmic triple mutant reveals a role for the circadian clock in cold stress response. Plant Cell Physiol 2009, 50:447-462.

9. Espinoza C, Bieniawska Z, Hincha DK, Hannah MA: Interactions between the circadian clock and cold-response in Arabidopsis. Plant Signal Behav 2008, 3:593-594.

10. Schliep A, Steinhoff C, Schonhuth A: Robust inference of groups in gene expression time-courses using mixtures of HMMs. Bioinformatics 2004, 20 (Suppl 1):i283-i289.

11. Verducci JS, Melfi VF, Lin S, Wang Z, Roy S, Sen CK: Microarray analysis of gene expression: considerations in data mining and statistical treatment. Physiol Genomics 2006, 25:355-363.

12. Dejean $S$, Martin PG, Baccini A, Besse P: Clustering time-series gene expression data using smoothing spline derivatives. EURASIP J Bioinform Syst Biol 2007, :70561.

13. Ernst J, Nau GJ, Bar-Joseph Z: Clustering short time series gene expression data. Bioinformatics 2005, 21(Suppl 1):i159-i168.

14. Hestilow TJ, Huang Y: Clustering of gene expression data based on shape similarity. EURASIP J Bioinform Syst Biol 2009, :195712.

15. Syeda-Mahmood T: Clustering time-varying gene expression profiles using scale-space signals. Proc IEEE Comput Soc Bioinform Conf 2003, 2:4856.

16. Koenig L, Youn E: Hierarchical Signature Clustering for Time Series Microarray Data: Software Tools and Algorithms for Biological Systems Volume 696, Advances in Experimental Medicine and Biology. New York: Springer; 2011:5765.

17. Chiappetta P, Roubaud MC, Torresani B: Blind source separation and the analysis of microarray data. J Comput Biol 2004, 11:1090-1109.

18. Salome PA, Xie Q, McClung CR: Circadian timekeeping during early Arabidopsis development. Plant Physiol 2008, 147:1110-1125.

19. Morker $\mathrm{KH}$, Roberts MR: Light exerts multiple levels of influence on the Arabidopsis wound response. Plant Cell Environ 2011, 34:717-728. 
20. Dong MA, Farre EM, Thomashow MF: Circadian clock-associated 1 and late elongated hypocotyL regulate expression of the C-REPEAT BINDING FACTOR (CBF) pathway in Arabidopsis. Proc Natl Acad Sci U S A 2011, 108:7241-7246.

21. Bar-Joseph Z, Gerber G, Simon I, Gifford DK, Jaakkola TS: Comparing the continuous representation of time-series expression profiles to identify differentially expressed genes. Proc Natl Acad Sci U S A 2003, 100:1014610151.

22. Edwards KD, Anderson PE, Hall A, Salathia NS, Locke JCW, Lynn JR, Straume M, Smith JQ, Millar AJ: Flowering locus $C$ mediates natural variation in the high-temperature response of the Arabidopsis circadian clock. Plant Cell Online 2006, 18:639-650

23. Harmer SL, Hogenesch JB, Straume M, Chang HS, Han B, Zhu T, Wang X, Kreps JA, Kay SA: Orchestrated transcription of key pathways in Arabidopsis by the circadian clock. Science 2000, 290:2110-2113.

24. Ptitsyn A: Comprehensive analysis of circadian periodic pattern in plant transcriptome. BMC Bioinforma 2008, 9:S18

25. Price TS, Baggs JE, Curtis AM, Fitzgerald GA, Hogenesch JB: WAVECLOCK: wavelet analysis of circadian oscillation. Bioinformatics 2008, 24:27942795.

26. Mockler TC, Michael TP, Priest HD, Shen R, Sullivan CM, Givan SA, McEntee C, Kay SA, Chory J: The DIURNAL project: DIURNAL and circadian expression profiling, model-based pattern matching, and promoter analysis. Cold Spring Harb Symp Quant Biol 2007, 72:353-363.

27. Lu Y, Rosenfeld R, Bar-Joseph Z: Identifying cycling genes by combining sequence homology and expression data. Bioinformatics 2006, 22:e314e322.

28. Wichert S, Fokianos K, Strimmer K: Identifying periodically expressed transcripts in microarray time series data. Bioinformatics 2004, 20:5-20.

29. Rustici G, Mata J, Kivinen K, Lio P, Penkett CJ, Burns G, Hayles J, Brazma A, Nurse $P$, Bahler J: Periodic gene expression program of the fission yeast cell cycle. Nat Genet 2004, 36:809-817.

30. Spellman PT, Sherlock G, Zhang MQ, lyer VR, Anders K, Eisen MB, Brown PO, Botstein D, Futcher B: Comprehensive identification of cell cycleregulated genes of the yeast Saccharomyces cerevisiae by microarray hybridization. Mol Biol Cell 1998, 9:3273-3297.

31. Whitfield ML, Sherlock G, Saldanha AJ, Murray Jl, Ball CA, Alexander KE, Matese JC, Perou CM, Hurt MM, Brown PO, Botstein D: Identification of genes periodically expressed in the human cell cycle and their expression in tumors. Mol Biol Cell 2002, 13:1977-2000.

32. Bozdech Z, Llinás M, Pulliam BL, Wong ED, Zhu J, DeRisi JL: The Transcriptome of the Intraerythrocytic Developmental Cycle of Plasmodium falciparum. PLOS Biol 2003, 1:e5.

33. Marks RJ II: Introduction to Shannon Sampling and Interpolation Theory. New York, USA: Springer; 1991

34. Craigon DJ, James N, Okyere J, Higgins J, Jotham J, May S: NASCArrays: a repository for microarray data generated by NASC's transcriptomics service. Nucleic Acids Res 2004, 32:D575-D577.

35. Parkinson H, Kapushesky M, Kolesnikov N, Rustici G, Shojatalab M, Abeygunawardena N, Berube H, Dylag M, Emam I, Farne A, et al: ArrayExpress update-from an archive of functional genomics experiments to the atlas of gene expression. Nucleic Acids Res 2009, 37: D868-D872.

36. Hubble J, Demeter J, Jin H, Mao M, Nitzberg M, Reddy TB, Wymore F, Zachariah ZK, Sherlock G, Ball CA: Implementation of GenePattern within the Stanford Microarray Database. Nucleic Acids Res 2009, 37:D898-D901.

37. Oran Brigham E: The fast Fourier transform and its applications. Upper Saddle River. NJ, USA: Prentice-Hall, Inc; 1988.

38. Tominaga D: Periodicity detection method for small-sample time series datasets. Bioinform Biol Insights 2010, 4:127-136.

39. Team RDC: R: A language and environment for statistical computing. Vienna, Austria: R Foundation for Statistical Computing; 2011.

40. Inc. TM: MATLAB: Massachusetts: Natick; 2010.

41. Harmer SL: The Circadian System in Higher Plants, Annu Rev Plant Biol. Volume 60. Palo Alto:; 2009:357-377. Annual Review of Plant Biology.

42. Nakamichi N: Molecular Mechanisms Underlying the Arabidopsis Circadian Clock. Plant Cell Physiol 2011, 52:1709-1718.

43. Li HM, Altschmied L, Chory J: Arabidopsis mutants define downstream branches in the phototransduction pathway. Genes Dev 1994, 8:339-349.

44. Lu SX, Tobin EM: Chromatin remodeling and the circadian clock: Jumonji C-domain containing proteins. Plant Signal Behav 2011, 6:810-814.
45. Mas P: Circadian clock function in Arabidopsis thaliana: time beyond transcription. Trends Cell Biol 2008, 18:273-281.

46. Thines B, Harmon FG: Four easy pieces: mechanisms underlying circadian regulation of growth and development. Curr Opin Plant Biol 2011, 14:3137.

47. Sinclair I, Dunton J: Electronic and Electrical Servicing: Consumer and commercial electronics. 2nd edition. Burlington, MA: Elsevier; 2007.

48. Chatterjee P, Mukherjee S, Chaudhuri S, Seetharaman G: Application Of PapoulisGerchberg Method In Image Super-Resolution and Inpainting. Comput J 2009, 52:80-89.

49. Orfanidis S: Introduction to signal processing. New Jersey, USA: Prentice Hall; 1995.

50. Fowler SG, Cook D, Thomashow MF: Low temperature induction of Arabidopsis CBF1, 2, and 3 is gated by the circadian clock. Plant Physiol 2005, 137:961-968

51. B-h L, Henderson DA, Zhu J-K: The Arabidopsis Cold-Responsive Transcriptome and Its Regulation by ICE1. Plant Cell Online 2005, 17:31553175 .

52. Bar-Joseph Z, Gerber GK, Gifford DK, Jaakkola TS, Simon I: Continuous representations of time-series gene expression data. J Comput Biol 2003, 10:341-356.

53. Smith AA, Craven M: Fast multisegment alignments for temporal expression profiles. Comput Syst Bioinformatics Conf 2008, 7:315-326.

54. Vogel JT, Zarka DG, Van Buskirk HA, Fowler SG, Thomashow MF: Roles of the CBF2 and ZAT12 transcription factors in configuring the low temperature transcriptome of Arabidopsis. Plant J 2005, 41:195-211.

55. Parodi S, Muselli M, Fontana V, Bonassi S: ROC curves are a suitable and flexible tool for the analysis of gene expression profiles. Cytogenet Genome Res 2003, 101:90-91.

56. Raychaudhuri S, Stuart JM, Altman RB: Principal components analysis to summarize microarray experiments: application to sporulation time series. Pac Symp Biocomput 2000, 5:455-466.

57. Gilmour SJ, Zarka DG, Stockinger EJ, Salazar MP, Houghton JM, Thomashow MF: Low temperature regulation of the Arabidopsis CBF family of AP2 transcriptional activators as an early step in cold-induced COR gene expression. Plant J 1998, 16:433-442.

58. Maruyama K, Sakuma Y, Kasuga M, Ito Y, Seki M, Goda H, Shimada Y, Yoshida S, Shinozaki K, Yamaguchi-Shinozaki K: Identification of coldinducible downstream genes of the Arabidopsis DREB1A/CBF3 transcriptional factor using two microarray systems. Plant J 2004, 38:982993.

59. Fowler S, Thomashow MF: Arabidopsis Transcriptome Profiling Indicates That Multiple Regulatory Pathways Are Activated during Cold Acclimation in Addition to the CBF Cold Response Pathway. The Plant Cell Online 2002, 14:1675-1690.

60. Hundertmark M, Hincha DK: LEA (late embryogenesis abundant) proteins and their encoding genes in Arabidopsis thaliana. BMC Genomics 2008, 9:118

61. Boerjan W, Ralph J, Baucher M: Lignin biosynthesis. Annu Rev Plant Biol 2003, 54:519-546.

62. Lacombe E, Hawkins S, Van Doorsselaere J, Piquemal J, Goffner D, Poeydomenge O, Boudet AM, Grima-Pettenati J: Cinnamoyl CoA reductase, the first committed enzyme of the lignin branch biosynthetic pathway: cloning, expression and phylogenetic relationships. Plant J 1997, 11:429441

63. Solecka D: Role of phenylpropanoid compounds in plant responses to different stress factors. Acta Physiologiae Plantarum 1997, 19:257-268.

64. Athanasiou K, Dyson BC, Webster RE, Johnson GN: Dynamic acclimation of photosynthesis increases plant fitness in changing environments. Plant Physiol 2010, 152:366-373.

65. Hannah MA, Wiese D, Freund S, Fiehn O, Heyer AG, Hincha DK: Natural genetic variation of freezing tolerance in Arabidopsis. Plant Physiol 2006 142:98-112

66. Onda Y, Yagi Y, Saito Y, Takenaka N, Toyoshima Y: Light induction of Arabidopsis SIG1 and SIG5 transcripts in mature leaves: differential roles of cryptochrome 1 and cryptochrome 2 and dual function of SIG5 in the recognition of plastid promoters. Plant J 2008, 55:968-978.

67. Yao J, Roy-Chowdhury S, Allison LA: AtSig5 Is an Essential NucleusEncoded Arabidopsis $\sigma$-Like Factor. Plant Physiol 2003, 132:739-747.

68. Swarbreck D, Wilks C, Lamesch P, Berardini TZ, Garcia-Hernandez M, Foerster H, Li D, Meyer T, Muller R, Ploetz L, et al: The Arabidopsis Information 
Resource (TAIR): gene structure and function annotation. Nucleic Acids Res 2008, 36:D1009-1014.

69. Soitamo A, Piippo M, Allahverdiyeva Y, Battchikova N, Aro E-M: Light has a specific role in modulating Arabidopsis gene expression at low temperature. BMC Plant Biology 2008, 8:13.

70. Ma S, Bohnert H: Integration of Arabidopsis thaliana stress-related transcript profiles, promoter structures, and cell-specific expression. Genome Biol 2007, 8:R49.

71. Xin Z, Mandaokar A, Chen J, Last RL, Browse J: Arabidopsis ESK1 encodes a novel regulator of freezing tolerance. Plant J 2007, 49:786-799.

72. Katoh A, Uenohara K, Akita M, Hashimoto T: Early steps in the biosynthesis of NAD in Arabidopsis start with aspartate and occur in the plastid. Plant Physiol 2006, 141:851-857.

73. Ruiz JM, Sanchez E, Garcia PC, Lopez-Lefebre LR, Rivero RM, Romero L: Proline metabolism and NAD kinase activity in greenbean plants subjected to cold-shock. Phytochemistry 2002, 59:473-478.

74. Vanderauwera S, Zimmermann P, Rombauts S, Vandenabeele $S$, Langebartels C, Gruissem W, Inzé D, Van Breusegem F: Genome-wide analysis of hydrogen peroxide-regulated gene expression in arabidopsis reveals a high light-induced transcriptional cluster involved in anthocyanin biosynthesis. Plant Physiol 2005, 139:806-821.

75. Stracke R, Ishihara H, Huep G, Barsch A, Mehrtens F, Niehaus K, Weisshaar B: Differential regulation of closely related R2R3-MYB transcription factors controls flavonol accumulation in different parts of the Arabidopsis thaliana seedling. Plant J 2007, 50:660-677.

76. Korn M, Peterek S, Mock HP, Heyer AG, Hincha DK: Heterosis in the freezing tolerance, and sugar and flavonoid contents of crosses between Arabidopsis thaliana accessions of widely varying freezing tolerance. Plant Cell Environ 2008, 31:813-827.

77. Jonassen $\mathrm{E}$, Lea $\mathrm{U}$, Lillo $\mathrm{C}$ : HY5 \& HYH are positive regulators of nitrate reductase in seedlings and rosette stage plants. Planta 2008, 227:559564.

78. Zhang Y, Zheng S, Liu Z, Wang L, Bi Y: Both HY5 and HYH are necessary regulators for low temperature-induced anthocyanin accumulation in Arabidopsis seedlings. J Plant Physio/ 2011, 168:367-374.

79. Sappl PG, Onate-Sanchez L, Singh KB, Millar AH: Proteomic analysis of glutathione $S$-transferases of Arabidopsis thaliana reveals differential salicylic acid-induced expression of the plant-specific phi and tau classes. Plant Mol Biol 2004, 54:205-219.

80. Lin WH, Ye R, Ma H, Xu ZH, Xue HW: DNA chip-based expression profile analysis indicates involvement of the phosphatidylinositol signaling pathway in multiple plant responses to hormone and abiotic treatments. Cell Res 2004, 14:34-45.

81. Vergnolle C, Vaultier M-N, Taconnat L, Renou J-P, Kader J-C, Zachowski A, Ruelland E: The cold-induced early activation of phospholipase C and D pathways determines the response of two distinct clusters of genes in arabidopsis cell suspensions. Plant Physiol 2005, 139:1217-1233.

82. Huang D, Wu W, Abrams SR, Cutler AJ: The relationship of drought-related gene expression in Arabidopsis thaliana to hormonal and environmental factors. J Exp Bot 2008, 59:2991-3007.

83. Kreps JA, Wu Y, Chang H-S, Zhu T, Wang X, Harper JF: Transcriptome changes for arabidopsis in response to salt, osmotic, and cold stress. Plant Physiol 2002, 130:2129-2141.

84. Tepperman JM, Hwang Y-S, Quail PH: phyA dominates in transduction of red-light signals to rapidly responding genes at the initiation of Arabidopsis seedling de-etiolation. Plant J 2006, 48:728-742.

85. Lee J, He K, Stolc V, Lee H, Figueroa P, Gao Y, Tongprasit W, Zhao H, Lee I, Deng XW: Analysis of transcription factor HY5 genomic binding sites revealed its hierarchical role in light regulation of development. The Plant Cell Online 2007, 19:731-749.

86. Larkindale J, Vierling E: Core genome responses involved in acclimation to high temperature. Plant Physiol 2008, 146:748-761

87. Li J, Brader G, Palva ET: The WRKY70 Transcription Factor: A Node of Convergence for Jasmonate-Mediated and Salicylate-Mediated Signals in Plant Defense. Plant Cell Online 2004, 16:319-331.

88. Hudson ME, Lisch DR, Quail PH: The FHY3 and FAR1 genes encode transposase-related proteins involved in regulation of gene expression by the phytochrome A-signaling pathway. Plant J 2003, 34:453-471.

89. Kumagai T, Ito S, Nakamichi N, Niwa Y, Murakami M, Yamashino T, Mizuno T: The common function of a novel subfamily of B-Box zinc finger proteins with reference to circadian-associated events in Arabidopsis thaliana. Biosci Biotechnol Biochem 2008, 72:1539-1549.

90. Tepperman JM, Hudson ME, Khanna R, Zhu T, Chang SH, Wang X, Quail PH: Expression profiling of phyB mutant demonstrates substantial contribution of other phytochromes to red-light-regulated gene expression during seedling de-etiolation. Plant J 2004, 38:725-739.

91. Khanna R, Shen Y, Toledo-Ortiz G, Kikis EA, Johannesson H, Hwang Y-S, Quail PH: Functional profiling reveals that only a small number of phytochrome-regulated early-response genes in arabidopsis are necessary for optimal deetiolation. Plant Cell Online 2006, 18:2157-2171.

doi:10.1186/1752-0509-6-69

Cite this article as: Rosa et al:: Frequency-based time-series gene expression recomposition using PRIISM. BMC Systems Biology 2012 6:69.

\section{Submit your next manuscript to BioMed Central and take full advantage of:}

- Convenient online submission

- Thorough peer review

- No space constraints or color figure charges

- Immediate publication on acceptance

- Inclusion in PubMed, CAS, Scopus and Google Scholar

- Research which is freely available for redistribution 